\title{
The effect of antituberculosis treatment on interferon- $\gamma$ release assay results
}

\author{
M. Bugiani1 , S. Bonora2, A. Carosso1, P. Piccioni1, \\ M. Cavallero1, A. Mondo3, V. Ghisetti3
}

\begin{abstract}
The effect of antituberculosis treatment on interferon- $\gamma$ release assay results. M. Bugiani, S. Bonora, A. Carosso, P. Piccioni, M. Cavallero, A. Mondo, V. Ghisetti.

Background and Aim. Monitoring the efficacy of antituberculosis therapy is crucial. The aim of this work is to investigate the effect of tuberculosis treatment on interferon- $\gamma$ response using Quanti-FERON@-TB Gold in tube (QFT-GIT).

Methods. A total of 216 new pulmonary tuberculosis (TB) cases were tested with QFT-GIT at the start of the treatment and, randomly, once or twice between 90 and 180 days afterwards. Data was analysed using the random effect regression model analysis.
\end{abstract}

Results. $63.4 \%$ of patients were positive at the QFTGIT (>.35 UI cut-off). TB cases showed a significant loglinear increase in interferon- $\gamma($ IFN- $\gamma)$ concentration, over time of treatment: IFN- $\gamma$ concentration increased by $78 \%$ after 6 months of treatment in acid-fast bacilli positive (A) and culture negative cases in culture confirmed cases the increase was $43 \%$ if $\mathrm{A}+$ and $20 \%$ in $\mathrm{A}-$.

Conclusions. Effective therapy seems to restore cellular responses to Mycobacterium tuberculosis antigens. The potential use of interferon gamma release assay (IGRA) in monitoring response to TB treatment is hampered by the presence of active mycobacterial replication at baseline and needs further evaluation.

Monaldi Arch Chest Dis 2011; 75: 4, 215-219.

Keywords: Pulmonary tuberculosis, Tuberculosis infection, Random effect model, Interferon-gamma assay, Monitoring therapy.

1 Unit of Pneumology Local Health Agency Turin 2 - Regional TB reference center, Turin,

2 Dept. of Infectious Diseases, University of Turin,

3 Laboratory of Microbiology, Amedeo di Savoia Hospital, Turin, Italy.

Correspondence: Massimiliano Bugiani, Unit of Pneumology ASL TO2, Lungo Dora Savona 26, 10131 Turin, Italy; e-mail: maxbugiani@libero.it

\section{Introduction}

It has been suggested that blood assays measuring interferon- $\gamma$ (INF- $\gamma$ ) production by lymphocytes exposed to specific Mycobacterium Tuberculosis (MTB) antigens may be useful in monitoring the efficacy of anti-tuberculosis therapy, but studies have provided conflicting results [1]. Some studies have shown that interferon- $\gamma$ response to ESAT-6 decreased more or less consistently during treatment in patients with active tuberculosis [2-4], while others have suggested that treatment could result either in increases [5-9] or in insignificant changes [1014], with both T-Spot and Quanti-FERONC-TB assays used for the study of INF- $\gamma$ release.

The aim of our study was to investigate the effect of tuberculosis treatment on INF- $\gamma$ response using Quanti-FERON@-TB Gold in tube (QFTGIT) in a randomly selected cohort of subjects with pulmonary tuberculosis undergoing anti-tuberculosis therapy.

\section{Methods}

Sequential randomisation was used to select 250 subjects among the new pulmonary TB cases diagnosed between 2006-2009 in the two main TB clinics in Turin, Italy. The study protocol was approved by the Turin-north ethics committee. Principal inclusion criteria were:

1) Pulmonary tuberculosis cases (excluding those with extra-pulmonary localisations) living in the Turin city area.

2) No previous anti-tuberculosis treatment.

3) Age: $>18$ and $<70$ years old.

4) Absence of HIV/AIDS or other severe comorbidity (e.g. cancer, DIMID) potentially affecting the degree of immune response.

5) The subject's informed consent.

Diagnosis of tuberculosis was consistent with

WHO and IUATLD recommendations $[15,16]$ :

- Clinical picture consistent with tuberculosis; bacteriologic confirmation (culture, gene probe/ $\mathrm{NAA} \pm \mathrm{AFB}$ smear); histological findings or

- Clinical picture consistent with tuberculosis; exclusion of other diagnostic considerations; typical response to antituberculosis treatment, quinolones excluded, and in the absence of other treatment.

Subjects were classified according to microbiological status before treatment as: acid-fast bacillus (AFB) positive and culture positive $(\mathrm{A}+\mathrm{C}+)$, AFB negative and culture positive $(\mathrm{A}-\mathrm{C}+)$ and AFB negative and culture negative (A-C-). 
The QFT-GIT assay was performed according to the manifacture's guidelines and calculations were carried out using the software provided by the firm (v2.5). Positive or negative tests are defined using a cut-off of $0.35 \mathrm{IU} / \mathrm{ml}$, following the manufacturer's recommendations. Data was reported in IU/ml and ln-transformed.

All subjects were tested with QFT-GIT at baseline and randomly (median 3 times per subject) between 90 and 180 days after standard treatment $(2 \mathrm{RHZ}(\mathrm{E})+4 \mathrm{RH})$ started (mean 169 days +/-40). The randomisation was performed by generating at each visit a random integer number between 1 and 3 and performing the test when the number was equal to 1.

Statistical analysis was performed as follows. Linear mixed effect models were fitted to the $1 n$ (QFT-GIT) values assuming they were approximately log-normally distributed. Residual plots from the fitted models showed this assumption was valid. Occasions of measurements were used as time variables.

In all models, main potential confounders (age, sex, migration) and case definition based on bacteriologic results (A-C-, A-C+, A+C+), months of treatment (time) and their interaction with confounders were considered as predictors. Following the Akaiki criteria, not significant confounders (at the $\mathrm{p}<0,05$ level) were excluded, retaining case definition, time and their interaction in all models [17].

\section{Results}

Of the 250 patients recruited, 34 were lost to follow up: 6 died and the others were transferred to other centres before completing two months of treatment. They were excluded from the analysis. Their mean age was 38 years old; 15 were born abroad, but living in Italy, 15 were AFB negative and culture negative (A-C-), 7 were AFB negative and culture positive (A-C+), and 7 were AFB positive and culture positive $(\mathrm{A}+\mathrm{C}+)$.

Of the 216 eligible subjects who completed the standard six-month treatment (2RHZE+4RH), 114 were A-C-, $40 \mathrm{~A}-\mathrm{C}+$ and $62 \mathrm{~A}+\mathrm{C}+; 12$ of the culture positive $(\mathrm{C}+)$ subjects remained culture positive after 3 months and were re-treated with second line drugs following sensitivity test; 6 of these remained positive also at six months and were considered treatment failures.

Table 1 reports the main characteristics of the 216 subjects studied.
At the baseline test, 137 (63.4\%) subjects were QFT-GIT positive $(>0.35 \mathrm{IU} / \mathrm{ml})$, specifically 67 $(58.8 \%)$ of the 114 A-C-, 29 (72.5\%) of the 40 A$\mathrm{C}+$, and $41(66.1 \%)$ of the $62 \mathrm{~A}+\mathrm{C}+$, with no statistically significant differences between groups. No QFT-GIT indeterminate result was observed.

A comparison of the baseline (table 2) quantitative measurements within the three study groups did not reveal any significant differences both with parametric and non parametric tests.

Regarding the transition probabilities over time of positive/negative QFT-GIT using the 0.35 threshold value, $37.4 \%$ of the 79 baseline negative subjects became positive (34\% of A-C-, $41 \%$ of A$\mathrm{C}+$ and $\mathrm{A}+\mathrm{C}+$ ) and $11.6 \%$ of the 137 baseline positive subjects became negative $(9.9 \%$ of A-C-, $15.6 \%$ of $\mathrm{A}-\mathrm{C}+$ and $11.6 \%$ of $\mathrm{A}+\mathrm{C}+$ ). Despite the high reversion and conversion rates, the proportion of conversions was higher than that of reversions in all the 3 bacteriological classes.

The results of random effect linear models are reported in table 3 .

Age and migration status had a significant effect: mean INF- $\gamma$ concentration was 25 -fold higher in foreigners than in Italian born subjects and it increased with age (1\% for each year). However, no significant interaction of these variables with length of treatment (in months) was detected. INF$\gamma$ concentration increased significantly over baseline values with length of treatment in A-C- $(10 \%$ per month), but less in C+ with a $3 \%$ monthly increase in A-and 6\% in A+.

Cumulative estimated INF- $\gamma$ increase versus baseline at month 6 of treatment was $78 \%$ in A-C, $20 \%$ in $\mathrm{A}-\mathrm{C}+$ and $43 \%$ in $\mathrm{A}+\mathrm{C}+$. The differences between the 3 bacteriological categories were not statistically significant at the $5 \%$ level either as mean values or changes over time.

Figure 1 reports the estimate QFT-GIT increase by month of treatment for the 3 bacteriological categories.

The figure shows overlay line plots of INF- $\gamma$ concentration by month of treatment in $\log _{\mathrm{e}}$ : starting at the lower basal level, after 6 months of treatment INF- $\gamma$ concentration for A-C-becomes similar to that of A-C+.

In the six subjects who failed to respond to treatment (failures), all with QFT-GIT>0.35 $\mathrm{IU} / \mathrm{ml}$, INF- $\gamma$ concentration remained substantially unchanged during treatment and all remained positive. Although no formal unbiased statistical test could be performed, due to the small number of

Table 1. - Main characteristics of the study population

\begin{tabular}{ccccc}
\hline $\begin{array}{c}\text { Bacteriological } \\
\text { category }\end{array}$ & $\begin{array}{c}\text { Age (years) } \\
\text { Mean } \pm \text { SD }\end{array}$ & $\begin{array}{c}\text { Gender (Males) } \\
\text { N and \% }\end{array}$ & $\begin{array}{c}\text { Foreign born } \\
\text { N and \% }\end{array}$ & $\begin{array}{c}\text { Number of subjects } \\
\text { N }\end{array}$ \\
\hline A-C- & $40.44 \pm 3.08$ & $56(49.1 \%)$ & $74(64.9 \%)$ & 114 \\
A-C+ & $45.73 \pm 5.58$ & $20(45 \%)$ & $22(55 \%)$ & 40 \\
A+C+ & $35.07 \pm 3.56$ & $35(56.5 \%)$ & $46(74.2 \%)$ & 62 \\
Total & $39.88 \pm 3.68$ & $111(51.3 \%)$ & $142(65.7 \%)$ & 216 \\
\hline
\end{tabular}

$\mathrm{A}=$ Acid - fast bacilli, $\mathrm{C}=$ culture, $\mathrm{m}=$ mean, $\mathrm{sd}=$ standard deviation. 
Table 2. - Baseline IFG- $\gamma$ measurement in IU/ml, by bacteriological category

\begin{tabular}{ccc}
\hline $\begin{array}{c}\text { Bacteriological } \\
\text { category }\end{array}$ & $\begin{array}{c}\text { Arithmetic } \\
\text { IU/ml } \\
\text { Mean } \pm \text { SD }\end{array}$ & $\begin{array}{c}\text { Geometric } \\
\text { Exp(In(IU/ml)) } \\
\text { Mean } \pm \text { SD }\end{array}$ \\
\hline A-C- & $3.24 \pm 4.15$ & $0.94 \pm 6.60$ \\
A-C+ & $5.13 \pm 9.88$ & $1.26 \pm 7.26$ \\
A+C+ & $3.95 \pm 5.41$ & $1.19 \pm 6.67$ \\
Total & $3.81 \pm 6.01$ & $1.06 \pm 6.74$ \\
\hline
\end{tabular}

ANOVA Test for geometric means: $\mathrm{F}=1.01, \mathrm{p}=.3638$. Median test: Pearson $\chi^{2}(2)=0.6535 \operatorname{Pr}=0.721$.

$\mathrm{A}=$ Acid - fast bacilli, $\mathrm{C}=$ culture, $\mathrm{m}=$ mean, $\mathrm{sd}=$ standard deviation.

subjects, no significant differences were detected in these subjects in comparison with the $\mathrm{A}+\mathrm{C}+$ whole group $(\mathrm{p}=.56)$.

\section{Discussion}

The main result of our study is that at the beginning of treatment INF- $\gamma$ concentration, as measured by QFT-GIT assay, depends on the bacteriological status (AFB and culture positive or not) and shows a log-linear increases during treatment in all subjects, although the increase was higher in subjects with a lower INF- $\gamma$ concentration at baseline.

Considering baseline test results, the sensitivity of the test (using the $0.35 \mathrm{UI} / \mathrm{ml}$ cut-off) is low, in accordance with other studies [18-21].

Cellular response to mycobacterial antigens, as measured by QFT-GIT, was significantly improved after chemotherapy and the effect seemed to be loglinear during treatment. A previous study [7] showed that after 2 months of treatment T-cells proliferation response was restored to the same level as 6 months after, without a linear relationship: however, this study was based on only 15 patients. Our study performed on a significantly larger number of individuals and the method of data collection (random assignation to the month of assay) and statistical analysis (random effect model) allowed a more accurate estimation of changes over time.

In accordance with other studies that have shown how cellular immune response to MTB increases with the length of anti-tuberculosis therapy [22], our data is consistent with this observation and is confirmed using MTB specific antigens instead of intact, non-specific MTB antigens. The restoration of the cellular response in TB patients receiving chemotherapy could be attributed to the increase in the proportion of peripheral CD4+ T cell INF- $\gamma$ producing or to increase of cell responsiveness [23]. According to this hypothesis, other studies have shown that $\mathrm{CD} 4+\mathrm{T}$ cells responsive to a large array of MTB epitopes are compartmentalised at the site of the disease, appearing in the peripheral blood after effective chemotherapy which reverses the state of relative hypoanergy usually observed in these patients [24, 25]. Other contributing factors in the restoration of cellular response could be the shift in cytokine production by mononuclear blood cells $[7,10,26]$.

Our findings are apparently in contrast with previous studies which show a significant INF- $\gamma$ decrease with treatment $[3,27]$. However, the decrease in specific T-cells is probably effectively contrasted by the short term cellular restoration, but the short length of our study does not allow further observations on this issue [28].

Another limitation of our study was the lack of T-cell measurement: however, only a minority of studies relied on cellular assessment, showing a firm correlation between mononuclear blood cell count and INF- $\gamma$ concentration [7].

In conclusion, our results suggest that effective anti-mycobacterial therapy could restore cellular response to MTB antigens, particularly in patients with a low bacterial load; inter-individual variability of the INF- $\gamma$ kinetic could explain to some ex-

Table 3. - Random Linear intercept effect model results using Ln-QFT-GIT as dependent and bacteriological categories (between), months of treatment (within) and their interaction as predictors, controlling for age standardized ((age-mean)/sd), sex and BCG status

\begin{tabular}{|c|c|c|c|c|c|c|}
\hline \multirow{2}{*}{$\begin{array}{c}\begin{array}{c}\text { Effect level } \\
\text { on Ln-QFT-GIT }\end{array} \\
\text { Between }\end{array}$} & \multirow{3}{*}{$\begin{array}{c}\text { Predictors } \\
\qquad \begin{array}{c}\text { A-C+ } \\
\mathrm{A}+\mathrm{C}+\end{array}\end{array}$} & \multirow{2}{*}{$\begin{array}{c}\text { Coef. B } \\
0.48\end{array}$} & \multicolumn{2}{|c|}{ [95\% Conf. Interval] } & \multirow{2}{*}{$\begin{array}{c}\mathbf{P}>\mathbf{z} \\
0.168\end{array}$} & \multirow{2}{*}{$\begin{array}{r}\operatorname{Exp}(B) \\
1.61\end{array}$} \\
\hline & & & 0.35 & 1.38 & & \\
\hline & & 0.43 & 0.30 & 1.42 & 0.155 & 1.53 \\
\hline Within & Month of tr. & 0.10 & 0.03 & 3.75 & 0.000 & 1.10 \\
\hline \multirow[t]{4}{*}{ Interactions } & $(\mathrm{A}-\mathrm{C}+)$ & & & & & \\
\hline & *month & -0.07 & 0.05 & -1.31 & 0.191 & 0.94 \\
\hline & $(\mathrm{A}+\mathrm{C}+)$ & & & & & \\
\hline & *month & -0.04 & 0.04 & -0.88 & 0.377 & 0.96 \\
\hline Constant & & -0.35 & 0.18 & -1.97 & 0.049 & 0.71 \\
\hline
\end{tabular}

Between: differences among subjects; within: changes with month of treatment by bacteriological status (A-C-as reference). $\mathrm{A}=$ Acid - fast bacilli, $\mathrm{C}=$ culture. 


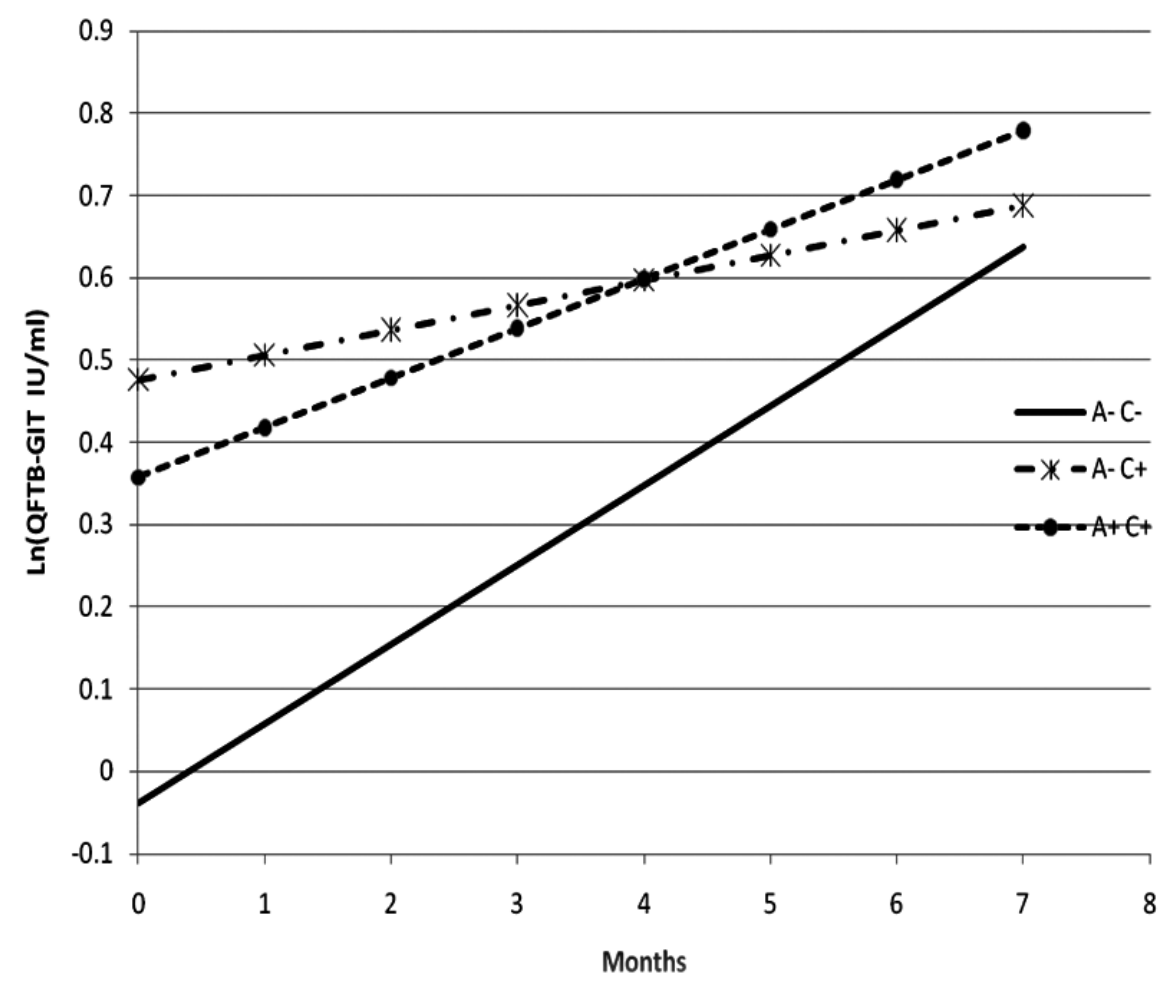

Fig. 1. - Mean Ln (QFT-GIT IU/ml) concentrations by month of treatment estimated by Random Effect model for the 3 bacteriological categories controlling for standardised age ((age-mean)/sd), sex, BCG status. Legend: $\mathrm{A}=\mathrm{Acid}-$ fast bacilli, $\mathrm{C}=$ culture .

tent conflicting results previously reported in literature, especially in studies based on very small sample size.

Finally, considering the low sensitivity and specificity versus the disease $[1,18-20]$, also evident from our results, and the well-known limitations of serial testing $[29,30]$, confirmed by the high reversion and conversion rates during treatment, the potential use of QFT-GIT as a tool for monitoring the response in the course of treatment appears to be limited.

Acknowledgements: We thank Dr. Susan P.S. Phillips, lector of English, for the language revision.

Funding: Study conducted with grants from Regione Piemonte-Progetti di ricerca sanitaria finalizzata 2005.

\section{References}

1. Pai M, Riley LW, Colford JM, Jr. Interferon-gamma assays in the immunodiagnosis of tuberculosis: a systematic review. Lancet Infect Dis 2004; 4: 761-776.

2. Lalvani A, Pathan AA, McShane $\mathrm{H}$, et al. Rapid detection of Mycobacterium tuberculosis infection by enumeration of antigen-specific T cells. Am J Respir Crit Care Med 2001; 163: 824-828.

3. Pathan AA, Wilkinson KA, Klenerman P, et al. Direct ex vivo analysis of antigen-specific IFN-gamma-secreting CD4 T cells in Mycobacterium tuberculosis-infected individuals: associations with clinical disease state and effect of treatment. J Immunol 2001; 167: 52175225.

4. Carrara S, Vincenti D, Petrosillo N, Amicosante M, Girardi E, Goletti D. Use of a T cell-based assay for mon- itoring efficacy of antituberculosis therapy. Clin Infect Dis 2004; 38: 754-756.

5. Ulrichs T, Anding R, Kaufmann SH, Munk ME. Numbers of IFN-gamma-producing cells against ESAT-6 increase in tuberculosis patients during chemotherapy. Int $J$ Tuberc Lung Dis 2000; 4: 1181-1183.

6. Ulrichs T, Moody DB, Grant E, Kaufmann SH, Porcelli SA. T-cell responses to CD1-presented lipid antigens in humans with Mycobacterium tuberculosis infection. Infect Immunol 2003; 71: 3076-3087.

7. Al-Attiyah R, Mustafa AS, Abal AT, Madi NM, Andersen P. Restoration of mycobacterial antigen-induced proliferation and interferon-gamma responses in peripheral blood mononuclear cells of tuberculosis patients upon effective chemotherapy. Immunol Med Microbiol 2003; 38: 249-256.

8. Vekemans J, Lienhardt C, Sillah JS, et al. Tuberculosis contacts but not patients have higher gamma interferon responses to ESAT-6 than do community controls in The Gambia. Infect Immunol 2001; 69: 6554-6557.

9. Sodhi A, Gong J, Silva C, Qian D, Barnes PF. Clinical correlates of interferon gamma production in patients with tuberculosis. Clin Infect Dis 1997; 25: 617-620.

10. Hirsch CS, Toossi Z, Othieno C, et al. Depressed T-cell interferon-gamma responses in pulmonary tuberculosis: analysis of underlying mechanisms and modulation with therapy. J Infect Dis 1999; 180: 2069-2073.

11. Wu-Hsieh BA, Chen CK, Chang JH, et al. Long-lived immune response to early secretory antigenic target 6 in individuals who had recovered from tuberculosis. Clin Infect Dis 2001; 33: 1336-1340.

12. Stuart RL, Olden D, Johnson PD, et al. Effect of antituberculosis treatment on the tuberculin interferongamma response in tuberculin skin test (TST) positive health care workers and patients with tuberculosis. Int $J$ Tuberc Lung Dis 2000; 4: 555-561. 
13. Fietta A, Meloni F, Cascina A, et al. Comparison of a whole-blood interferon-gamma assay and tuberculin skin testing in patients with active tuberculosis and individuals at high or low risk of Mycobacterium tuberculosis infection. Am J Infect Control 2003; 31: 347-353.

14. Ravn P, Demissie A, Eguale T, et al. Human T cell responses to the ESAT-6 antigen from Mycobacterium tuberculosis. J Infect Dis 1999; 179: 637-645.

15. Williams VG. Tuberculosis: clinical features, diagnosis and management. Nurs Stand 2006; 20: 49-53.

16. Rieder HL, Watson JM, Raviglione MC, Forssbohm M, Migliori GB, Schwoebel V, Leitch AG, Zellweger JP. Surveillance of tuberculosis in Europe. Working Group of the World Health Organization (WHO) and the European Region of the International Union Against Tuberculosis and Lung Disease (IUATLD) for uniform reporting on tuberculosis cases. Eur Respir J 1996; 9: 1097-1104.

17. Skrondal AR-H, S. Multilevel logistic regression for polytomous data and rankings. Psychometrika 2003; 68: 267-287.

18. Pai M, Zwerling A, Menzies D. Systematic review: Tcell-based assays for the diagnosis of latent tuberculosis infection: an update. Ann Intern Med 2008; 149: 177-184.

19. Pai M, Menzies D. Interferon-gamma release assays: what is their role in the diagnosis of active tuberculosis? Clin Infect Dis 2007; 44: 74-77.

20. Pai M, Joshi R, Bandyopadhyay M, et al. Sensitivity of a whole-blood interferon-gamma assay among patients with pulmonary tuberculosis and variations in T-cell responses during anti-tuberculosis treatment. Infection 2007; 35: 98-103.

21. Pai M. Alternatives to the tuberculin skin test: interferon-gamma assays in the diagnosis of mycobacterium tuberculosis infection. Indian J Med Microbiol 2005; 23: $151-158$.
22. Dieli F, Friscia G, Di Sano C, et al. Sequestration of T lymphocytes to body fluids in tuberculosis: reversal of anergy following chemotherapy. J Infect Dis 1999; 180: 225-228.

23. Shams H, Wizel B, Weis SE, Samten B, Barnes PF. Contribution of $\mathrm{CD} 8(+) \mathrm{T}$ cells to gamma interferon production in human tuberculosis. Infect Immunity 2001; 69: 3497-3501.

24. Jurcevic S, Hills A, Pasvol G, Davidson RN, Ivanyi J, Wilkinson RJ. T cell responses to a mixture of Mycobacterium tuberculosis peptides with complementary HLA-DR binding profiles. Clin Exp Immunol 1996; 105: 416-421.

25. Wilkinson RJ, Vordermeier HM, Wilkinson KA, et al. Peptide-specific T cell response to Mycobacterium tuberculosis: clinical spectrum, compartmentalization, and effect of chemotherapy. J Infect Dis 1998; 178: 760-768.

26. Garcia M, Vargas JA, Castejon R, Navas E, Durantez A. Flow-cytometric assessment of lymphocyte cytokine production in tuberculosis. Tuberculosis 2002; 82: 37-41.

27. Andersen ABP. Proteins and antigens of Mycobacterium tuberculosis. In: Bloom B e, ed. Tuberculosis. ASM Press, Washington, DC, 1994; pp. 307-332.

28. Pai M, Joshi R, Dogra S, et al. Persistently elevated T cell interferon-gamma responses after treatment for latent tuberculosis infection among health care workers in India: a preliminary report. J Occup Med Toxicol (London, England) 2006; 1: 7.

29. Pai M, O'Brien R. Serial testing for tuberculosis: can we make sense of $\mathrm{T}$ cell assay conversions and reversions? PLoS medicine 2007; 4: e208.

30. Chung WK, Zheng ZL, Kim HS, et al. Serial testing of interferon-gamma-release assays for the diagnosis of latent tuberculosis in hemodialysis patients. Infect 2010; 61: 144-149.

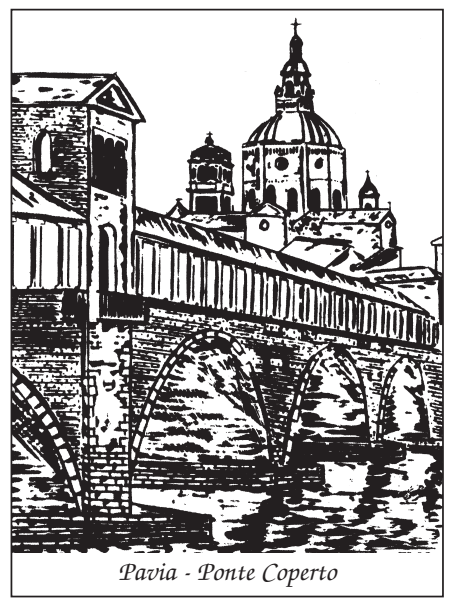

